\title{
Kâğıt Fabrikası Arıtım Suyu Çamurunun Diğer Atık Kâğıtlarla Birlikte Ambalaj Kartonu Üretiminde Değerlendirilmesi
}

\author{
Evaluation of Paper Mill Treatment Water Sludge in Container Box Cardboard Production \\ with Other Waste Papers
}

\author{
Selim KARAHAN* ${ }^{1, a}$, Arif KARADEMIR ${ }^{2, b}$ \\ ${ }^{1}$ Gümüşhane Üniversitesi, Kürtün MYO, Ormancılık Bölümü, 29810 Kürtün, Gümüşhane \\ ${ }^{2}$ Bursa Teknik Üniversitesi, Orman Fakültesi, Orman Endüstri Mühendisliği Bölümü, Osmangazi, Bursa
}

• Geliş tarihi / Received: 02.08.2019 • Düzeltilerek geliş tarihi / Received in revised form: $22.10 .2019 \quad$ • Kabul tarihi / Accepted: 24.10 .2019

\begin{abstract}
$\ddot{O} z$
Günümüz sanayinin hılı bir şekilde gelişme göstermesi, beraberinde su kirliliğini de getirmektedir. Özellikle günümüzde doğanın rastgele sanayi atık suları ile kirletilmesi canlı ve cansız her şeyi de etkilemektedir. Bu sorunun çözümü için suyu yoğun bir şekilde kullanan endüstriyel tesisler atık suyu arıtma tesislerinde arıttıktan sonra doğaya vermektedir. Kâğıt fabrikaları da suyu yoğun olarak kullanan endüstrilerin başında gelmektedir. Bu gibi tesislerde suyun arıtılması sonucunda atık çamur oluşmaktadır. Bu çamur geri yıkama suyu ile birlikte doğaya bırakılmaktadır. Burada âtıl durumda bulunan çamuru değerlendirerek ülke ekonomisine bir katkı sağlanması düşünülmektedir. Hem bu sayede atık çamurda tekrar geri dönüşüme girerek hem insanlar hem de doğa için faydalı bir duruma dönüşmüş olacaktır. Bu araştırmada atık kâğıt işleyen Kahramanmaraş Kâğıt Fabrikasından (KMK) üretim sonrası elde edilen atık çamur kullanılmıştır. Bu çamur içerisine çeşitli işlemlerden sonra kil, kalsiyum karbonat, nişasta, reçine vs eklenip malzeme üretilmiştir. Daha sonra bu malzemelere press uygulanmıştır. Daha sonra ise bu malzemelerin kurutulması sağlanmıştır. En sonunda ise bütün üretilen malzemeler için laboratuvar testleri yapılmıştır. Atık kâğıt karışımına belirlenen oranlarda katılan atık çamur ile yapılan testler sonucunda; kopma indis değeri ve patlama indis değerinde \%5' lik atık çamur katılımında max. değere ulaşmıştır. Diğer taraftan cobb ve hava geçirgenliği değerlerinde ise bir azalış meydana getirir iken kül değerinde ise bir artış meydana gelmiştir.
\end{abstract}

Anahtar kelimeler: Atık Su, Çamur, Çevre, Kâğıt Fabrikası, Karton

\begin{abstract}
Today, the increase of industry rapidly, water pollution was caused Especially, the pollution of nature with random industrial wastewater were affected all living and non-living organism. For the sollution of this problem, after treatment wastewater were purified by industrial mills used intensive water. The paper mills are also the one of the industries which use the water intensive. In these mills consisted of waste sludge. This sludge is left to nature with backwashing water. It is thought that it contributes to the national economy by evaluating the sludge in the waste way. In this way, waste sludge also by entering recycle will have transformed again a helpful case for both people and nature. In this study, waste sludge obtained from Kahramanmaras Paper Mill (KMK), which processes wastepaper, was used. After various processes, clay, calcium carbonate, starch, resin etc. Were added to this slurry to produce the material. Then, press was applied to these materials. Then these materials were dried. Finally, laboratory tests were performed for all produced materials. As a result of the tests carried out with the waste sludge added to the wastepaper mixture in the specified ratios; breakage index value and burst index value of $5 \%$ of waste sludge participation max. has reached the value. On the other hand, cobb and air permeability values decreased while ash value increased.
\end{abstract}

Keywords: Wastewater, Sludge, Environment, Papermill, Cardboard

\footnotetext{
$*^{\text {a }}$ Selim KARAHAN; selimkarahan @msn.com, Tel: (0456) 2331018 (dâhili: 3402), orcid.org/0000-0002-8499-2427

${ }^{\mathrm{b}}$ orcid.org/0000-0003-0924-2156
} 


\section{Giriş}

Atık kâğıt fabrikası atık su arıtma işlemleri sonrası açığa çıkan çamurunun uzaklaştırılması ciddi bir problemdir. Çevre mevzuatına göre araziye atmak veya gömmek metoduyla bu çamurun yok edilmesi mümkün ve pratik görülmemektedir. Bu çamurun farklı bir metot ile yeni bir ürüne dönüştürülmesi hem de yüksek kaliteli bir ürün elde edilmesiyle çevresel bir problemin çözümü hedeflenmektedir. Bahsedilen atık çamur, zengin inorganik içeriği ve lif kırıntıları nedeniyle doğal olarak kompozit üretimine uygun bir karışım olarak görülmektedir. $\mathrm{Bu}$ atık çamur ile farklı bileşen ve katkılarla özellikleri iyileşmiş çok daha kaliteli ürünler elde edilmesi amaçlanmıştır. Bu sayede hem değersiz bir çamurun uzaklaștırılması konusundaki problemlerin ortadan kaldırılması sağlanacak hem de tamamen hammadde bakımından yeni ve değerli bir ürün elde edilmesi mümkün olacaktır. Suların çeșitli kullanımlar sonucunda atık su haline dönüşerek kaybettikleri fiziksel, kimyasal ve bakteriyolojik özelliklerinin bir kısmını veya tamamını tekrar kazandırmak için yapılan, ayrıca atıldıkları ortamın doğal fiziksel, kimyasal, bakteriyolojik ve ekolojik özelliklerini değiştirmeyecek hale getirebilmek için yapılan fiziksel, kimyasal ve biyolojik arıtma işlemlerinin her birine atık su arıtma işlemi denilmektedir (Eroğlu, 2004).

Kâğıt fabrikaları arıtım suyunda oluşan atık çamur içerisinde fazla miktarlarda selüloz lifi ve inorganik maddeler bulunmaktadır. $\mathrm{Bu}$ atık çamurun rutubet miktarı ise \%60-75 arasında değişim göstermektedir (Ishimito, 2000; Ahmadi ve Al-Khaja, 2001). Fabrika kaynaklı atık sular otomatik temizlemeli kaba 1zgaradan geçmektedir. $\mathrm{Bu}$ 1zgara ile atık su içerisinde bulunan elyaf, kâğıt, naylon, iplik vb. katı parçaların tutulması sağlanmaktadır. Atık su arıtma işlemi ile atık sularda kirliliğe neden olan çözünmüş ve askıdaki maddelerin uzaklaştırılmasını sağlanmıştır (Eroğlu, 2004). Kâğıt hamuru ve kâğgt üretim fabrikalarında arıtma sularında oluşan atık çamur içerisinde değerlendirilebilmesi mümkün fazla miktarlarda organik madde bulunmaktadır. (Naik vd., 2004).

Yapılan bir çalışmada kâğıt fabrikalarının arıtma suyu çamurunun çimentolu yongalevha üretiminde katk1 maddesi olarak kullanım olanakları araştırılmıştır. $\mathrm{Bu}$ amaçla kâğıt fabrikası arıtma suyu çamuru çimentoya oranla $\% 10, \% 20$ ve $\% 30$ olarak kullanılmıştır (Çavdar vd., 2011). Diğer bir çalışmada ise kağıt fabrikası arıtma suyu çamurunun yakılması sonucunda elde edilen kül'ün portlant çimentoyla \%10 oranında eklenmesiyle oluşan materyalin fiziksel özelliklerinin yükseldiği belirtilmiştir (Fava vd., 2011).

$\mathrm{Bu}$ araştırmanın testleri Kahramanmaraş Sütçü İmam Üniversitesi Orman Endüstri Mühendisliği Bölümü kâğıt laboratuvarında yapılmıştır.

\section{Materyal ve Metot}

\subsection{Materyal}

Araştırmada materyal olarak arıtım suyu çamuru yanında ilave olarak atık oluklu mukavva, ofis kâğıdı, gazete kâğıdı, dolgu maddesi olarak ta $\left(\mathrm{CaCO}_{3}\right)$ kullanılmıştır. Ayrıca kâğıdın suya karşı direncini artırmak için Alkil Keten Dimer (AKD) ve tutundurucu madde olarak (PAC ve Polimin SK) ilavesi yapılmıştır. Çalışmada kullanılan oluklu mukavva, ofis kâğıdı ve gazete kâğıdı oranları Tablo 1'de verilmiştir. Daha sonra bu atık kâğıt karışımlarına belli oranlarda atık çamur ilavesi yapılmıştır.

Tablo 1. Çalışmada karışımı yapılan atık kâğıtların yüzde kullanım oranları

\begin{tabular}{l|c}
\hline Atık Kâğı Örnekleri & \% \\
\hline Oluklu Mukavva & 40 \\
Ofis Kâğıdı & 40 \\
Gazete Kâğıdı & 20 \\
\hline
\end{tabular}

\subsection{Metot}

\subsubsection{Hamur Hazırlama}

Farklı atık kâğıt sınıfından gazete kâğıdı, ofis kâğıdı ve oluklu mukavva kâğgtları toplanmıştır. $\mathrm{Bu}$ atık kâğıtlar tabloda (Tablo 1) verilen oranlarda tartılarak su içerisinde $20^{\circ} \mathrm{C}$ 'de 12 saat bekletilmiştir. Tam islanan kâğıtların disintegratörde $5 \mathrm{dk}$ açılması sağlanmıştır. Daha sonra kâğıt hamurları hazırlanmıştır. Tablo 1'de verilen atık kâğıt karışımına $\% 5,10,15$ ve 20 oranlarında çamur karıştırılarak deneme kâğıtları hazırlanmıştır.

Gramaj1 $150 \mathrm{~g} / \mathrm{m}^{2}$ olması düşünülen deneme kâğıtları ve atık çamur numunesi için \% kuruluk miktarları belirtilen formüle göre (Formül 1) hesaplanmıştır. Atık kâğıtların her biri ve çamur numunesi için hava kurusu ölçüleri alınmaktadır $\left(\mathrm{M}_{\mathrm{i}}\right)$, daha sonra bu ölçüler alındıktan sonra firın kurusu ağırlıkları için $103 \pm 2^{\circ} \mathrm{C}$ etüv firınında 4 saat kurutulduktan sonra tartılıp kuru ağırlıkları 
bulunur $\left(\mathrm{M}_{\mathrm{s}}\right)$. Bulunan değerler ilgili formülde yerine yazılarak 150 gr' da kâğıt yapmak için gerekli kuruluk yüzdeleri hesaplanır (Eroğlu, 2004). Elde edilen hamur süspansiyonu ise elek alanı $200 \mathrm{~cm}^{2}$ olan mekanik el kâğıdı üretim düzeneğinde (British Handsheet Former) belirlenen metoda (TAPPI $\mathrm{T}$ 205) göre test kâğıtları üretilmiştir.

Farklı atık kâğıt sınıfları ile atık çamura ait ortalama kuruluk değerleri Tablo 2'de verilmiştir.

Tablo 2. Çalışmada kullanılan arıtma çamuru ile atık kâğıtların ortalama kuruluk oranları

\begin{tabular}{lccc}
\hline \multirow{2}{*}{ Atık Kâğıt Örnekleri } & $\begin{array}{c}\text { Hava Kurusu (g) } \\
\mathrm{M}_{\mathrm{i}}\end{array}$ & $\begin{array}{c}\text { Tam Kuru (g) } \\
\mathbf{M}_{\mathrm{s}}\end{array}$ & Ortalama Kuruluk (\%) \\
\hline Oluklu Mukavva & 10.32 & 9.68 & 93.79 \\
Ofis (A4) & 10.03 & 9.55 & 95.21 \\
Gazete & 10.46 & 9.52 & 91.01 \\
Arıtma Çamuru & 7.32 & 2.30 & 31.42 \\
\hline
\end{tabular}

Ortalama kuruluk $(\%)=\frac{\mathrm{Ms}}{\mathrm{Mi}} \times 100$

\subsubsection{Kâğgt Testleri}

$\mathrm{Bu}$ çalışmada üretilen kâğıtların testleri KSÜ Orman Fakültesi Kâğı Laboratuvarında gerçekleştirilmiştir. Çalışmada önce oluklu mukavva, ofis kâğıdı ve gazete kâğ 1 dı karışımları hamurlaştırılmış daha sonra belirlenen bu karışıma $\% 5,10,15$ ve 20 oranlarında arıtma suyu çamuru ilavesi yapılarak test kâğgtları üretilmiştir. Daha sonra kâğıtlar Regmed Makinesi'nde her bir yüzü $5 \mathrm{dk}$ kurutulması sağlanmıştır. Elde edilen bu deneme kâğıtlarına aşağıda belirtilen testler uygulanmiştır.

- Kopma testi (TAPPI T 494)

- Patlama testi (TAPPI T 403)

- Kül tayini (TAPPI T 211)

- Rutubet tayini (TAPPI T 412)

- Hava geçirgenliği (TAPPI T 547)

- Cobb testi (TAPPI T 441)

\section{Bulgular ve Tartışma}

Kâğıdın üretim aşamasında arıtım suyu çamurlarının içerisindeki kimyasalların (Katyonik retensiyon, Anyonik retensiyon, Şap, Pac, reçine, AKD, CMC, Bünye, Nişasta, Yüzey nişasta, köpük söndürücü, zift önleyici, polielektrolit) bir kısmının üretilen kâğıt içerisinde tutulamadığı için elek altına geçip kaybolmaktadır. Kâğıdın mukavemetini artırmak ve atı su arıtma çamurlarının içerisindeki çeşitli kimyasalları tekrardan kâğıt içerisine kazandırılması için çeşitli kimyasal maddeler ve dolgu maddeleri kullanılabilir. $\mathrm{Bu}$ ise fazladan bir maliyet oluşturmaktadır. Atık olan çamuru değerlendirmek ise daha verimli ekonomik olmaktadır. Çalışmada üretilen el kâğıtlarına dolgu maddesi olarak kalsiyum karbonat $\left(\mathrm{CaCO}_{3}\right)$, kâğıdın su emiciliğini azaltmak için alkil keten dimer (AKD), Sentetik ve selülozlarla reaksiyona girebilen Poly Alüminyum Klorür (PAC) ve Polymin Sk gibi kimyasallar kullanıldı. Üretilen deneme kâğıtlarında belli oranlarda atık çamur katılımı sağlanmıştır. (İlk aşamada üretilen test kâğıtlarına $\% 0$ çamur ve $\% 0$ kimyasal kullanılmıştır). Yapılan çalışmalar sonucu üretilen test malzemelerine ait testler şekillerde verilmiştir (Şekil 1-5).

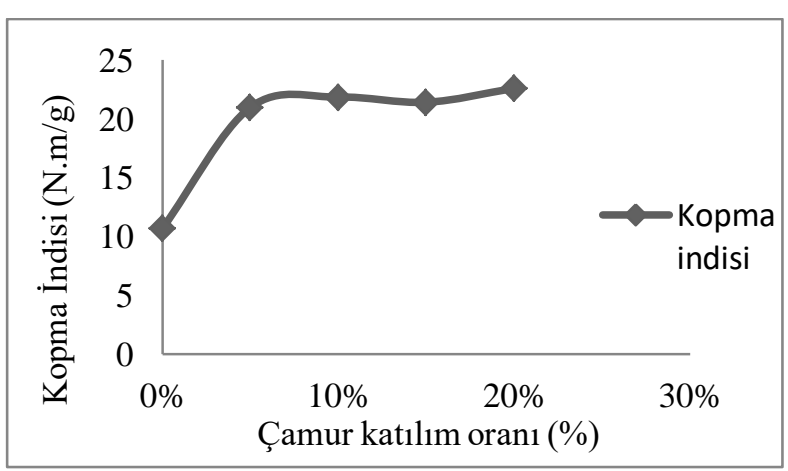

Şekil 1. Atık kâğıt karışımı içerisine belli oranlarda atık çamur katılımının kopma indisi üzerine etkisi

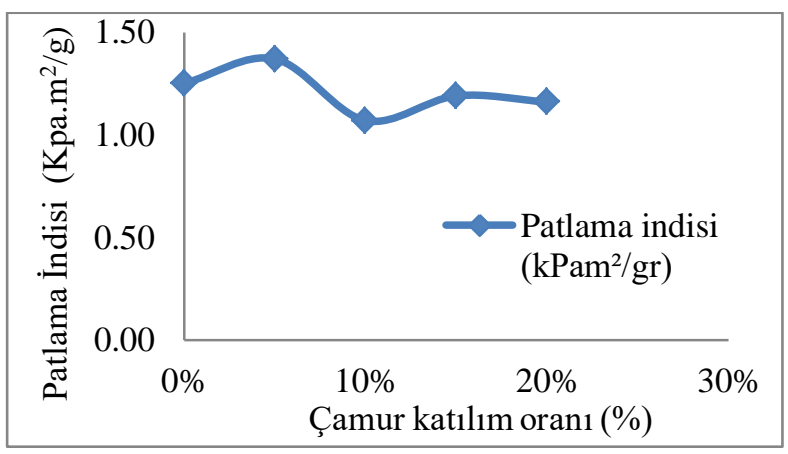

Şekil 2. Atık kâğıt karışımına belli oranlarda atık çamur katılımının patlama indisi üzerine etkisi 
Belirlenen oranlarda hazırlanan atık kâğıt karışımına (oluklu mukavva + ofis kâğıd $1+$ gazete kâğ1d1), yine belirlenen oranlarda atık çamur ilavesi yapılmıştır. Bunun sonucundaki kopma indis değeri \%5'lik atık çamur katılımında max. değere ulaşmıştır. $\mathrm{Bu}$ değerden sonra ise grafikte fazla bir değişiklik olmamıştır (Şekil 1). Patlama indis değerinde ise $\% 5^{\prime}$ lik atık çamur katılımında max. değere ulaşmıştır. Ancak bu değerden sonra grafikte dalgalı bir azalma meydana gelmiştir (Şekil 2).

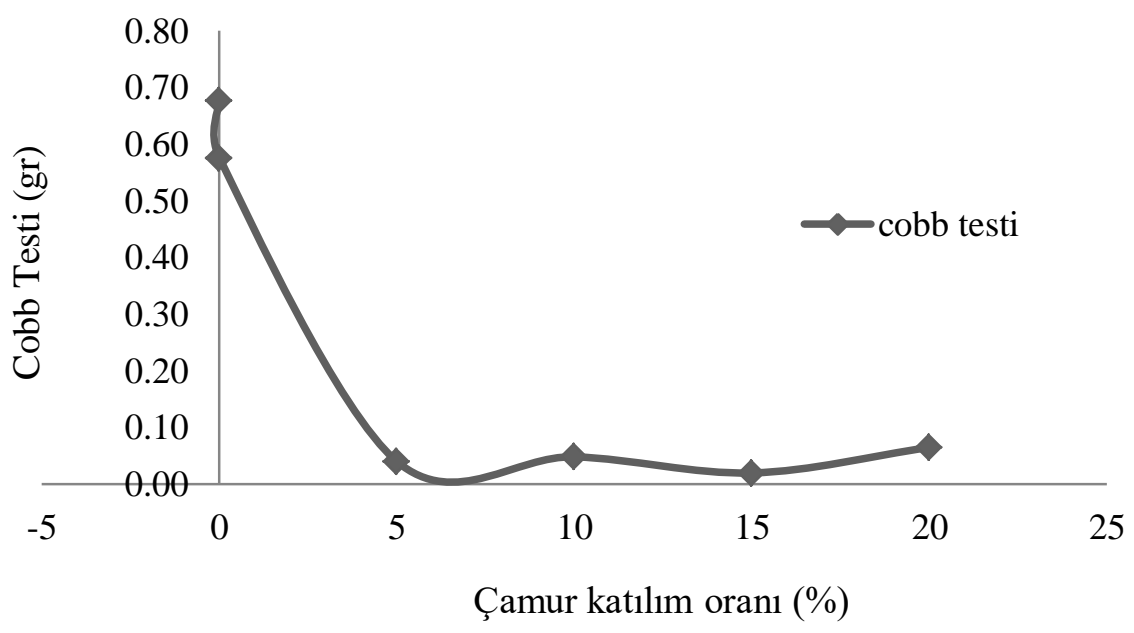

Şekil 3. Atık kâğıt karışımına belli oranlarda atık çamur katılımının cobb üzerine etkisi

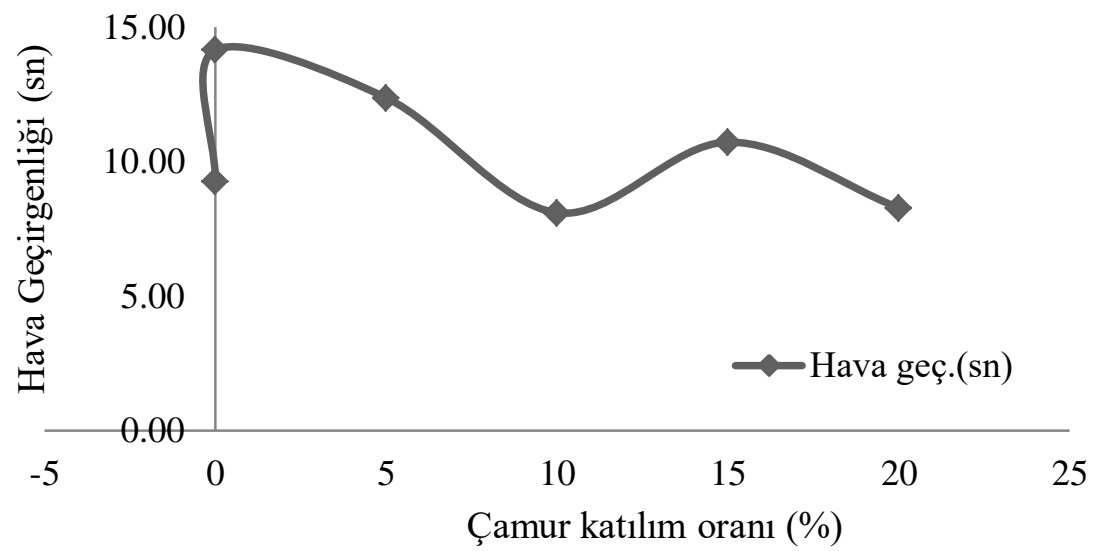

Şekil 4. Atık kâğıt karışımına belli oranlarda atık çamur katılımının hava geçirgenliği üzerine etkisi

Atık kâğıt karışımına (oluklu mukavva + ofis kâğ $1 d_{1}+$ gazete kâğ $1 d_{1}$ ) yine belirlenen oranlarda atık çamur ilavesi yapılmıştır. Bunun sonucunda cobb ve hava geçirgenliği değerlerinde, bir azalış meydana getirmiştir (Şekil 3 ve 4). Bu durum ise atık çamur miktarının atık kâğıt karışım süspansiyona katılım miktarı arttıkça yoğunluk ve gözenekliğin artmasından kaynaklandığ 1 söylenebilir.

Atık kâğıt karışımına (oluklu mukavva + ofis kâğıdı + gazete kâğıdı) yine belirlenen oranlarda atık çamur ilavesi yapılmıştır. Bunun sonucunda ise kül değerinde, bu oranlara paralel olarak bir artış meydana gelmiştir (Şekil 5). Bu durum ise artan çamur miktarı ile beraber artan inorganik miktarındaki artıştan kaynaklandığı söylenebilir.

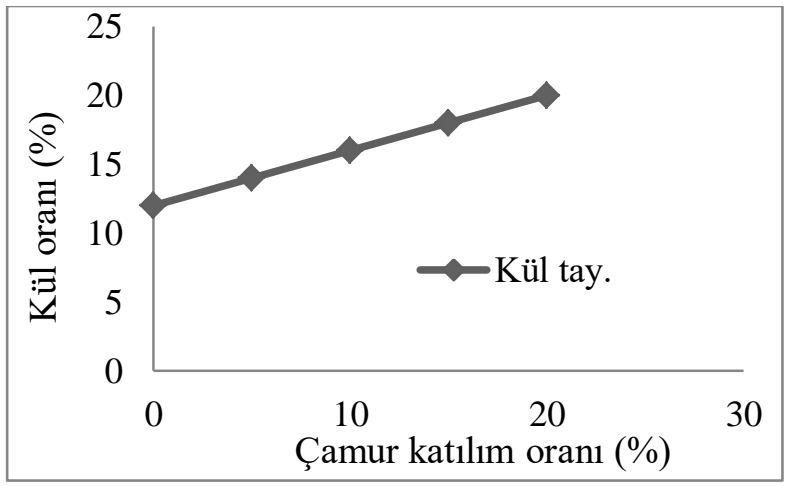

Şekil 5. Atık kâğı̀t karışımına belli oranlarda atık çamur katılımının kül üzerine etkisi 
Kâğıt fabrikalarının atık sularında oluşan çamurların çimentolu yonga levhalar için suda bekletme süreleri arttıkça su alma oranlarında da bir artış gözlenmiştir. Diğer yandan atık çamur kullanımı levhaların çekme direnci üzerinde ciddi bir etki oluşturmamıştır. Fakat eğilmede elastikiyet modülü değerleri ise atık çamur miktarı arttıkça buna paralel olarak bir artış kaydedilmiştir (Çavdar vd., 2012).

Atık su arıtımı sonucunda, atık çamur yoğunlaştırma havuzunda aktif çamur içerisindeki $\% 0,5 \sim 1$ olan katı madde miktarı \%5 seviyesine yükselir. Oluşan çamurun hacmini azaltmak, susuzlaştırmak ve verimini yükseltmek amacıyla atık çamura kireç ve polielektrolit kimyasalı katılmaktadır. Bu sayede kuru katı miktar1 \%2530 seviyesine çıkmaktadır. Son olarak ta elde edilen atık çamur kamyonlara yüklenip tesisten uzaklaştırılmaktadır (Eroğlu, 2004).

Atık kâğıtların yeniden üretiminde amaca göre çok değişik kimyasallar ve katkı maddeleri farklı oranlarda kullanılmaktadır. Bunlar arasında dolgu maddeleri önemli bir yer tutmaktadır. Dolgu maddesi suda çok az çözünen veya hiç çözünmeyen inorganik yapıdaki küçük boyutlardaki mineral maddeler ifade edilmektedir (Kırc1, 2004).

Kâğıt fabrikaları arıtım suyu çamurunda inorganik madde olarak kaolinit ve kalsiyum karbonat bulunmaktadır. Ayrıca bu atık çamurun içerisinde kağıt yapımında kullanılmakta olan yüzey aktif ajanları ile yazı ve boya baskılarda kullanılmakta olan bazı ağır metallerde azda olsa bulunabilir (Ishimito, 2000; Ismail vd., 2010).

Herhangi bir kullanım alanında fonksiyonunu tamamlayan ve atılan her türlü kâğıt, karton ve mukavvalar atık kâğıt olarak kabul edilmektedir (Kırc1, 2000). Atık kâğıtların geri dönüşümündeki esas amaç; çok farklı kaynaklardan gelen ve homojen bir yapı sergilemeyen atık kâğıt hammaddesini istenilen türdeki kâğıt üretimi için uygun özellikte olan temiz ve homojen bir hamura çevirmektir (Kırc1, 2006).

\section{Sonuç ve Öneriler}

Test sonuçlarına genel olarak bakıldığında; hamur süspansiyonuna atık çamur katıldığında patlama ve kopma indis değerlerinde biraz düşüş yaşanmış, buna karşın malzemenin su alma ve hava geçirgenliği değerlerinde ise biraz dalgalanmalar yaşanmıştır. Malzemenin hava geçirgenliği ve cobb (su tutma) değerlerinde ise;
AKD kimyasalı kullanıldığı için kâğıdın su alma özelliği ve hava geçirgenliği azalmış daha sonra sabit kalmıştır. Çalışmada dolgu maddesi kullanıldığı için kâğıdın mukavemet değerleri (patlama indis -kopma indis) düşmüştür. Dolgu maddesi ve atık çamur kullanımı artıkça malzemedeki kül miktarı da (inorganik madde) artmıştır. Kâğıt fabrikasından alınan atık çamurun içerisinde çok çeşitli atık materyaller bulundurmaktadır. $\mathrm{Bu}$ yüzden çalışmada kullanılan tutundurucu kimyasalların hamurda fazla tutunmamış ve bu kimyasalların elek altına kaçması ile de üretilen malzemelerin mukavemet değerlerinin düştüğü söylenebilir.

Kâğıt hamuru içerisine atık çamur katılarak elde edilen bu malzeme binalarda yalitım veya dolgu maksatlı kullanılacaksa eğer üretilen bu malzemeye yapılan test değerlerindeki ufak tefek dalgalanmalarda bu çalışma için bertaraf edilebilir. Çünkü çalışma konusu olan atık çamur, atık işleyen bir işletmenin üretim atığının değerlendirilmesi üzerine yoğunlaştırılmıştır. $\mathrm{Bu}$ anlamda değersiz bir atık olan çamur değerlendirilerek hem çevre açısından olumsuzluklarını ortadan kaldırılması hem de üretilen malzemenin maliyetini düşürmek için değerli bir ürün elde edilmiştir Şekil 6' da kartondan imal edilebilecek bir ürünün sadece tek kat bir taslağı görülmektedir. Kâğıt ve karton üretim aşamalarında bu tabakaların kalınlık ve katmanlarının ihtiyaca göre istenildiği kadar arttırılması mümkün olabilmektedir.

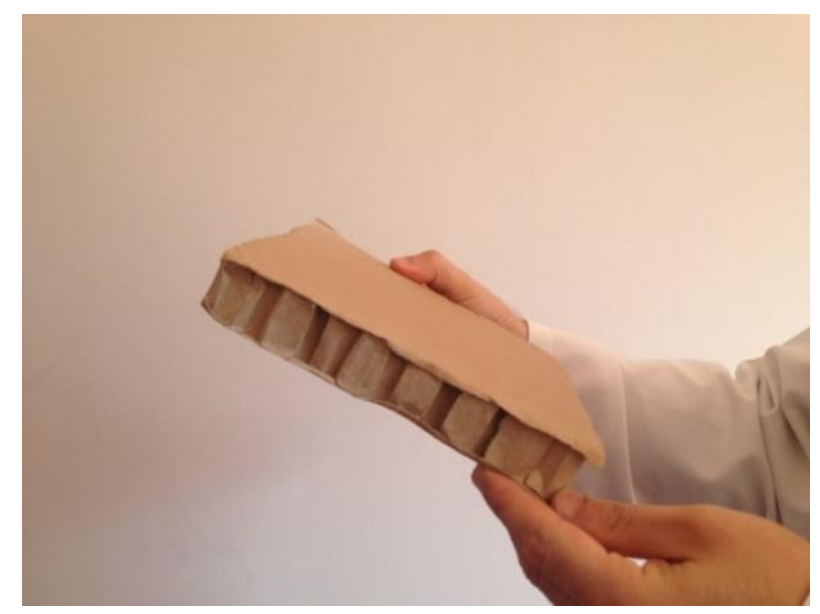

Şekil 6. Çeşitli birleştirmeler ile elde edilen kartondan levha (alt, üst ve ara kat tek tabakalı)

$\mathrm{Bu}$ kâğıt ürünü karton koli üretiminde kullanılabileceği gibi çeşitli kalınlıklarda üretilerek kap1 vs gibi yap1 elemanlarının ara bölmelerinde dolgu materyali olarak ayrıca ses ve 1s1 yalıtım materyali olarak değerlendirilmesi olanaklı görülmektedir. 


\section{Teşekkür}

$\mathrm{Bu}$ çalışma, Gümüşhane Üniversitesi Bilimsel Araştırma Projeleri (GÜBAP) Koordinatörlügü tarafindan desteklenmiştir Proje No: 13.B0822.02.01.

\section{Kaynaklar}

Ahmadi, B. ve Al-Khaja, W. 2001. Utilization of paper waste sludge in the building construction industry. ELSEVIER: Resources, Conservation and Recycling. 32, $105-113$.

Çavdar, A.D., Yel, H., Kalaycıŏ̆lu, H. ve Aras, U., 2012. Kağıt Fabrikası Arıtım Suyu Çamuru ile Üretilen Çimentolu Yonga levhaların Fiziksel ve Mekaniksel Özellikleri. KSÜ Mühendislik Bilim Dergisi Özel Sayı, I. Ulusal Akdeniz Orman ve Çevre Sempozyumu, 26-28 Ekim 2011, Kahramanmaraş, Türkiye, s. 69-73.

Eroğlu, H. ve Usta, M. 2004. Kâğıt ve Karton Üretim Teknolojisi, KTÜ, Trabzon.

Fava, G., Ruello, M. L. ve Corinaldesi, V. 2011. Paper Mill Sludge Ash as Supplementary Cementitious Material. Journal of Materials in Civil Engineering, 23(6), 772-776.

Ishimoto, H., 2000. Use of papermaking sludge as new material. J. Mater. in Eng., 12, 310-313.

Ismail, C. M., Ismail, M.A., Lau, S.K., Muhammad, B. ve Majid, Z., 2010. Fabrication of bricks from paper sludge and palm oil fuel ash. Concrete Research Letters, Vol. 1(2).

Kırcı, H. 2000. Atık Kâğıt Geri Kazanma Teknolojisi, KTÜ Basımevi, Trabzon.

Kırcı, H. 2006. Kâğıt Hamuru Endüstrisi Ders Notları, KTÜ Yayın, No 86, Trabzon.

Naik, T. R., Friberg, T. S. ve Chun, Y-C. 2004. Use of pulp and paper mill residual solids in production of cellucrete. Cem. Concr. Res., 34(7), 12291234.

TAPPI T 205 sp-06, 1992. Forming Handsheets for physical Test of Pulp. Tappi Test Methods, Tappi Pres, Atlanta, 2.

TAPPI T 211 om-85, 1992. Ash in Wood and Pulp. Tappi Test Methods, Tappi Pres, Atlanta, 1.

TAPPI T 403 om-91, 1992. Bursting Strength of paper. Tappi Test Methods, Tappi Pres, Atlanta, 2.

TAPPI T 412-om-90, 1992. Moisture in Paper and Paperboard. Tappi Test Methods, Tappi Pres, Atlanta, 2.

TAPPI T 441-om-04, 1998. Kâğıt için Cobb Değeri Tayini.

TAPPI T 494-om-88, 1998. Kâğıt için Kopma Değeri Tayini.

TAPPI T 547 om-12, 1992. Air Permeance of Paper and Paperboard. Tappi Test Methods, Tappi Pres, Atlanta, 2. 